\title{
Short-term Clinical Outcomes Based on Risk Factors of Recurrence after Removing Common Bile Duct Stones with Endoscopic Papillary Large Balloon Dilatation
}

\author{
Jung Ho Kim, Yeon Suk Kim, Dong Kyu Kim, Min Su Ha, Young Jun Lee, Jong Joon Lee, \\ Sang Jin Lee, In Sik Won, Yang Suh Ku, Yun Soo Kim and Ju Hyun Kim \\ Department of Internal Medicine, Gachon University Gil Hospital, Gachon University of Medicine and Science, Incheon, Korea
}

Background/Aims: Recurrence is an important late complication of endotherapy of bile duct stones. Endoscopic papillary large balloon dilation (EPLBD) can be used as an alternative method of removing difficult bile duct stones. The aim of this study was to evaluate short term clinical outcomes after removing common bile duct (CBD) stones using EPLBD.

Methods: A retrospective review was performed based on the medical records of 141 patients who received EPLBD, with or without endoscopic sphincterotomy, between September 2008 and February 2010. Of these, 50 patients, were enrolled in the study. Clinical and endoscopic parameters were analyzed to identify risk factors for CBD stones recurrence.

Results: Male:Female ratio was 22:28 (mean age, $67.4 \pm 14.4$ years). Recurrence rate was $24.0 \%(12 / 50)$. Mean follow-up period was $10.8 \pm$ 4.5 months. Nineteen (38.0\%) had a history of surgery and $20(40.0 \%)$ were comorbid with periampullary diverticula. Mean diameters of the stones and CBD were $13.8 \pm 4.3 \mathrm{~mm}$ and $20.1 \pm 7.2 \mathrm{~mm}$, respectively. In univariate analysis, large CBD stones ( $\geq 12 \mathrm{~mm})$ and angulated $\mathrm{CBD}$ (angle $\leq 145^{\circ}$ ) were identified as the significant predictors of recurrence. In multivariate analysis, angulated $\mathrm{CBD}\left(\right.$ angle $\left.\leq 145^{\circ}\right)$ was the significant independent risk factor for recurrence.

Conclusions: Close follow-up seems necessary in patients with angulated CBD (angle $\leq 145^{\circ}$ ).

Key Words: Endoscopic papillary large balloon dilatation; Common bile duct stones; Recurrence; Risk factors

\section{INTRODUCTION}

Endoscopic sphincterotomy (EST) using endoscopic retrograde cholangiopancreatography (ERCP) is currently the primary treatment in removing common bile duct (CBD) stones, with more than $90 \%$ of success rate.$^{1-3}$ However, endoscopic stone extraction is not easy when the stones are big or placed above a stricture. Since the introduction of endoscopic papillary large balloon dilation (EPLBD) after limited EST by Ersoz

Received: March 31, 2011 Revised: November 24, 2011

Accepted: December 12, 2011

Correspondence: Yeon Suk Kim

Division of Gastroenterology, Department of Internal Medicine, Gachon University Gil Hospital, Gachon University of Medicine and Science, $1198 \mathrm{Guwol}$ 1-dong, Namdong-gu, Incheon 405-760, Korea

Tel: +82-32-460-3778, Fax: +82-32-460-3408

E-mail: drkim@gilhospital.com

(c) This is an Open Access article distributed under the terms of the Creative Commons Attribution Non-Commercial License (http://creativecommons.org/ licenses/by-nc/3.0) which permits unrestricted non-commercial use, distribution, and reproduction in any medium, provided the original work is properly cited. et al. ${ }^{4}$ the combination of EPLBD plus EST is being applied to the removal of CBD stones unmanageable with conventional methods.

The recurrence rate of bile duct stones after EST is estimated around $5 \%$ to $21 \%$, which is reported to be associated with several factors. ${ }^{1,5-8}$ There are few studies, however, reporting factors associated with the recurrence of CBD stones after EPLBD. This study was conducted to determine the short-term followup results, especially the recurrence data, in patients who received EPLBD plus limited EST or EPLBD alone.

\section{MATERIALS AND METHODS}

\section{Patients}

The study was performed in patients whose radiologic imaging data (abdominal ultrasonography, abdominal computed tomography $[\mathrm{CT}]$, and magnetic resonance cholangiopancreatography) were available, among those who visited Ga- 
chon University Gil Hospital for CBD stone removal between September 2008 and February 2010, and was followed for at least 6 months after EPLBD with limited EST or EPLBD alone. Exclusion criteria were follow-up without imaging studies, history of stone removal with EPLBD, surgery due to the failure of endoscopic stone extraction, and concomitant pancreatobiliary cancer. Eligible patients were followed with CT at 6 months after the EPLBD alone or EPLBD with limited EST. Patients were treated again with EPLBD only or in combination with the limited EST, in case stones were detected during the follow-up in some cases, recurrent stones were treated by Dormia baskets or retrieval balloon without EPLBD or EST. CTs were performed at 6 months interval after the removal of stones or when symptoms occur.

A total of 141 patients were treated with EPLBD only or in combination with the limited EST to remove CBD stones; and 50 patients among these, who were available for follow-up with abdominal CTs for more than 6 months, were enrolled in the study.

\section{Methods}

Every endoscopy was performed by two experienced, more than 350 cases of annual ERCP volume, endoscopist (YS Kim or YS Ku), using side-viewing duodenoscopy (TJF-240; Olympus Optical Co., Tokyo, Japan). All participants provided written informed consent. Endoscopies were performed under conscious sedation by intravenous injection of midazolam (2-3 $\mathrm{mg}$ ) and fentanyl $(100-150 \mu \mathrm{g})$ or by intravenous injection of midazolam (2-3 mg) plus intramuscular injection of meperidine (25-50 mg), according to the endoscopists' decision based on the patient's age and weight. Ten milligram of cimetropium bromide was administered, if necessary, after reaching the descending duodenum. After selective cannulation of the CBD, with cannula or pull-type papillotome, a cholangiogram was obtained to measure the stone size, $\mathrm{CBD}$ diameter, distal CBD angulation ( $\mathrm{CBD}$ angle) and the length of the distal $\mathrm{CBD}$ arm. Limited EST was performed in patients without pervious EST experience; slightly extended EST was performed, if necessary, in patients with pervious EST experience. After inserting a guidewire, limited EST was performed by $1 / 3$ of maximum incision of the papillary roof using standard pull-type papillotome (MTW Endoskopie, Wesel, Germany). As the electrosurgical unit, UES-30 (Olympus Optical Co.), with $40 \mathrm{~W}$ of blended current, consisted of repeating short cutting current and then coagulation current, was used. A 12-20 mm of balloon catheter (controlled radial expansion balloon; Microvasive, Boston Scientific Co., Natick, MA, USA) was used according to the endoscopists' decision based on CBD diameter and stone size. The middle portion of the balloon was placed at the site of the biliary sphincterotomy; the balloon was grad- ually inflated until achieving complete disappearance of its waist portion on cholangiogram under the fluoroscopic guidance, immediately or maintained at least over 45 seconds after which the balloon was contracted; and then the stones were extracted using Dormia basket and retrieval balloon. A mechanical lithotripter was used when this procedure failed to extract the stones. In case of incomplete stone removal, endoscopic retrograde biliary drainage, followed by additional ERCP, were performed. Serum amylase and lipase were measured at 4 hours and 24 hours after removing the stones; liver function test and $\mathrm{CBC}$ were also performed, if necessary.

\section{Outcome measurement and definitions}

Pi-View PACS (Infinitt, Seoul, Korea) program was used for every measurement of sizes, lengths, and angles. Distal CBD angulation and the length of distal CBD arm were measured in accordance with the criteria proposed by Kim et al. ${ }^{9}$ Periampullary diverticulums (PAD) were categorized into 3 types based on the report by Lobo et al. ${ }^{10}$ Complications were classified as suggested by Cotton et al. ${ }^{11}$ and the stone recurrence was defined as the detection of a stone on CT images taken at least 6 months after confirming that the stone was completely removed on the final cholangiogram.

\section{Statistical analysis}

Kaplan-Meier method was used to analyze the association between risk factors and recurrence. Significant factors found in univariate analysis were analyzed in multivariate analysis with Cox regression to control confounding variables such as age and sex. Continuous variables were expressed as mean and standard deviation (SD). SPSS Windows version 12.0 (SPSS Inc., Chicago, IL, USA) statistical program was used for the analysis and $p<0.05$ was considered to indicate statistical significance.

\section{RESULTS}

\section{Patient characteristics}

The participants included 22 men (44.0\%) with a mean \pm SD age of $67.4 \pm 14.4$ years. Recurrence was confirmed in $12(24.0 \%)$ out of 50 patients. The number of patients with previous cholecystectomy and Billoth II gastrojejunostomy were 17 (34.0\%) and $2(4.0 \%)$, respectively. Twelve patients (24.0\%) previously received endoscopic stone extraction with EST. PAD was found in 20 patients (40.0\%); with type 1 in 2 patients (4.0\%), type 2 in 12 patients (24.0\%) and type 3 in 6 patients (12.0\%). The mean follow-up period was $10.8 \pm 4.5$ months, and the time to recurrence, among patients with recurrence, was $12.8 \pm 5.6$ months (Table 1). 
Table 1. Characteristics at the Time of Intial ERCP in 50 Patients

\begin{tabular}{lc}
\hline Characteristic & Value \\
\hline Age, yr & $67.4 \pm 14.4$ \\
Gender & \\
Male & $22(44.0)$ \\
Female & $28(56.0)$ \\
Previous surgery & \\
Cholecystectomy & $17(34.0)$ \\
Billoth II gastrojejunostomy & $2(4.0)$ \\
Previous ERCP & \\
Previous EST & $12(24.0)$ \\
Baseline laboratory finding & \\
AST, IU/L & $141.9 \pm 206.6$ \\
ALT, IU/L & $120.5 \pm 131.3$ \\
ALP, IU/L & $171.6 \pm 112.8$ \\
Total bilirubin, mg/dL & $3.7 \pm 4.6$ \\
Periampullary diverticulum & \\
Type $1^{\text {a) }}$ & $2(4.0)$ \\
Type 2 & $12(24.0)$ \\
Type $3^{\text {c) }}$ & $6(12.0)$ \\
Total & $20(40.0)$ \\
Follow-up interval, mo & $10.8 \pm 4.5$ \\
\hline Vas &
\end{tabular}

Values are presented as mean \pm SD or number (\%).

ERCP, endoscopic retrograde cholangiopancreatography; EST, endoscopic sphncterotomy; AST, aspartate aminotransferase; ALT, alanine aminotransferase; ALP, alkaline phosphatase.

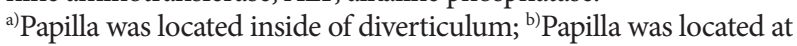
lower rim of diverticulum; ${ }^{\mathrm{c}}$ Papilla was located outside of diverticu$\operatorname{lum}(<2 \mathrm{~cm})$.

\section{Results of CBD stone removal with EPLBD}

The average maximum diameter (size) of CBD stones was $13.8 \pm 4.3 \mathrm{~mm}$, and multiple stones were found in 31 patients (62.0\%). The average maximum diameter of the balloon catheters used for the procedure was $16.0 \pm 2.4 \mathrm{~mm}$; with $12 \mathrm{~mm}$ balloon catheter in 9 patients (18.0\%), $15 \mathrm{~mm}$ in 17 patients (34.0\%), $18 \mathrm{~mm}$ in 22 patients (44.0\%) and $20 \mathrm{~mm}$ in 2 patients $(4.0 \%)$. The maximum diameter of the dilated CBD was $20.1 \pm 7.2 \mathrm{~mm}$, the length of the distal CBD arm was $41.3 \pm 13.6$ $\mathrm{mm}$, and distal CBD angle was $145.9 \pm 15.3^{\circ}$. Twenty patients (40.0\%) received more than 2 ERCPs for stone removal, and 1 patient (2.0\%) received mechanical lithotripsy (Table 2).

\section{Complications of EPLBD only or in combination with Limited EST}

Mild pancreatitis occurred in 7 patients (14.0\%) after ERCP, but severe pancreatitis was not reported. There was no hemorrhage or perforation as much as to require transfusion or to cause significant decrease in hemoglobin level (Table 3).

\section{Risk factors of CBD stone recurrence}

A univariate analysis was performed, considering the fol-
Table 2. Results of Endoscopic Stone Removal after EPLBD

\begin{tabular}{lc}
\hline Characteristic & Value \\
\hline CBD stone & \\
$\quad$ Size of largest stone, mm & $13.8 \pm 4.3$ \\
Multiple stones $\geq 2$ & $31(62.0)$ \\
Diameter of balloon dilatation & \\
12 mm & $9(18.0)$ \\
15 mm & $17(34.0)$ \\
18 mm & $22(44.0)$ \\
20 mm & $2(4.0)$ \\
Total & $16.0 \pm 2.4$ \\
Characteristics of CBD & \\
Largest bile duct diameter, mm & $20.1 \pm 7.2$ \\
CBD arm, mm & $41.3 \pm 13.6$ \\
CBD angle, degree & $145.9 \pm 15.3$ \\
Complete stone removal in multiple $(\geq 2)$ session & $20(40.0)$ \\
Mechanical lithotripsy performed & $1(2.0)$ \\
\hline
\end{tabular}

Values are presented as mean \pm SD or number (\%).

EPLBD, endoscopic papillary large balloon dilation; CBD, common bile duct.

Table 3. Complications of EPLBD in 50 Patients

\begin{tabular}{ll}
\hline Complication & No. $(\%)$ \\
\hline Hemorrhage after ERCP & $0(0)$ \\
Perforation & $0(0)$ \\
Documented pancreatitis after ERCP & $7(14.0)$ \\
Total & $7(14.0)$ \\
\hline
\end{tabular}

$\overline{\text { EPLBD, endoscopic papillary large balloon dilation; ERCP, endoscopic }}$ retrograde cholangiopancreatography.

low-up period, to identify risk factors of CBD stone recurrence (Table 4). The result suggested that the previous cholecystectomy, concomitance of PAD and combination with EST were not statistically significant risk factors of recurrence, nor the presence of multiple stones. However, CBD stones $\geq 12 \mathrm{~mm}$ in diameter were found to be a statistically significant risk factor of recurrence $(p=0.041)$. CBD angulation $\leq 145^{\circ}$ was also found as a significant risk factor of recurrence $(p=0.002)$, although the maximum CBD diameter of $15 \mathrm{~mm}$ or more and distal CBD arm of $36 \mathrm{~mm}$ or less were not found as statistically significant risk factors. The diameter of balloon catheters used for the procedure ( $\geq 18 \mathrm{~mm}$ ) and the number of ERCPs performed for stone removal (more than twice) were not significant risk factors of recurrence either.

In multivariate analysis, $\mathrm{CBD}$ angulation $\leq 145^{\circ}$ was found as the independent risk factor of recurrence (relative risk, 8.556; 95\% confidence interval [CI], 1.580-46.317; $p=0.013$ ), but not CBD stone more than $12 \mathrm{~mm}$ (Table 5).

\section{DISCUSSION}

ERCP and EST are regarded as a standard treatment to re- 
Table 4. Univariate Analysis of Risk Factors for Recurrent CBD Stones after EPLBD

\begin{tabular}{lccc}
\hline Variable & No recurrence $(n=38)$ & Recurrence $(n=12)$ & $p$-value \\
\hline Patient-related factors & & & $6(50.0)$ \\
Age $\geq 65$ & $23(60.5)$ & $6(50.0)$ & 0.914 \\
Male sex & $16(42.1)$ & $5(41.7)$ & 0.836 \\
Previous cholecystectomy & $12(31.6)$ & $3(25.0)$ & 0.740 \\
Previous EST & $9(23.7)$ & $4(33.3)$ & 0.403 \\
Periampullary diverticulum & $16(42.1)$ & $11(91.7)$ & 0.917 \\
Stone size $\geq 12$ mm & $23(60.5)$ & $7(58.3)$ & 0.041 \\
Multiple stones $\geq 2$ & $24(63.2)$ & $11(91.7)$ & 0.706 \\
CBD diameter $\geq 15$ mm & $26(68.4)$ & $5(41.7)$ & 0.195 \\
CBD arm $\leq 36$ mm & $15(39.5)$ & $8(66.7)$ & 0.361 \\
Angulated CBD (angle $\left.\leq 145^{\circ}\right)$ & $15(39.5)$ & & 0.002 \\
Procedure related factors & & $7(58.3)$ & 0.213 \\
Balloon diameter $\geq 18$ mm & $17(44.7)$ & $5(41.7)$ & 0.781 \\
Multiple endoscopic session $\geq 2$ & $15(39.5)$ & & \\
\hline
\end{tabular}

Values are presented as number (\%).

CBD, common bile duct; EPLBD, endoscopic papillary large balloon dilation; EST, endoscopic sphncterotomy.

Table 5. Multivariate Analysis of Risk Factors for Recurrent CBD Stones after EPLBD

\begin{tabular}{lcc}
\hline \multicolumn{1}{c}{ Variable } & Relative risk $(95 \% \mathrm{CI})$ & $p$-value \\
\hline Stone size $\geq 12 \mathrm{~mm}$ & $5.998(0.667-53.917)$ & 0.110 \\
Angulated CBD $\left(\right.$ angle $\left.\leq 145^{\circ}\right)$ & $8.556(1.580-46.317)$ & 0.013 \\
\hline
\end{tabular}

CBD, common bile duct; EPLBD, endoscopic papillary large balloon dilation; $\mathrm{CI}$, confidence interval.

place surgery in most cases of CBD stones. ${ }^{1,2,5}$ Endoscopic papllirary balloon dilation (EPBD) without EST is often used for some patients with high bleeding tendency or when the function of Oddi sphincter is to be maintained. ${ }^{12,13}$ The combination therapy of EPLBD and EST has been reported, since its first report in 2003, to have relatively high success rate and low complication rate in various patient groups, ${ }^{4,14}$ making it a suitable option when removing biliary stones not manageable with conventional EST. ${ }^{15,16}$

The recurrence of CBD stone is a serious late complication, which might cause recurrent cholangitis and secondary biliary cirrhosis, or even death due to sepsis when cholangitis was occurred in old or immunocompromised patients. The recurrence of CBD stones, after endoscopic extraction, occurs within 3 years in most cases, at about $5 \%$ to $21 \%$ of frequency. ${ }^{1,5-8} \mathrm{Di}$ lated $\mathrm{CBD}$, presence of $\mathrm{PAD}$, history of previous cholecystectomy and $\leq 145^{\circ}$ of distal $\mathrm{CBD}$ angulation have been reported to be associated with recurrence so far. ${ }^{5,6,17}$ Dilated CBD (>15 $\mathrm{mm}$ ) and history of previous cholecystectomy have been reported as the risk factors of recurrence after EPBD. ${ }^{18}$ There have been various reports on risk factors associated with $\mathrm{CBD}$ stone recurrence after EST, ${ }^{1,5,6,17,19}$ but there are few studies yet on the risk factors of recurrence after stone removal with EPLBD.

In this study, $12 \mathrm{~mm}$ or more maximum stone diameter and $145^{\circ}$ or less distal $\mathrm{CBD}$ angulation were found as significant factors in univariate analysis, and $145^{\circ}$ or less distal CBD angulation was found as an independent risk factor in multivariate analysis (relative risk, 8.556; 95\% CI, 1.580-46.317; $p=0.013$ ). The presence of PAD was reported, in some studies, to be associated with stone production and recurrence, but other studies reported that there was no association between them. ${ }^{11,20,21}$ The findings of this study suggested that the existence of PAD was not associated with the recurrence after removing stones with EPLBD, neither the type of PAD (data not shown). EPLBD seems more efficient, compared to EST, in treating difficult biliary stones with $\mathrm{PAD}$, since it enables sufficient distention of the major papillary orifice, which is why our study concluded that EPLBD would not cause any technical difficulty or affect the recurrence rate with or without PAD.

Kim et al. ${ }^{9}$ suggested 65 years or older age, history of gastrojejunostomy, short $(\leq 36 \mathrm{~mm})$ distal CBD arm and acute $\left(\leq 135^{\circ}\right)$ distal CBD angle as factors causing technical difficulty in endoscopic removal of biliary stones. The current study, however, found that recurrence was not affected by the patient's age, surgical history and length of distal CBD arm. The length of distal CBD arm may be regarded as an anatomical feature that might influence technical difficulty, as suggested in previous studies on recurrence after EST, but not as a contributing factor to stone recurrence. ${ }^{22}$

In our study, distal CBD angle of $135^{\circ}$ or less was not found as a risk factor of stone recurrence, but distal CBD angle of $145^{\circ}$ or less found as an independent risk factor of stone recurrence in the multivariate analysis, as reported by Keizman et al. ${ }^{6}$ Distal CBD angle occurs naturally when CBD is curved to the right side before meeting the duodenum, and is considered to cause cholestasis. ${ }^{6}$ It is reasonable to speculate that 
bile stasis will become worse as the distal CBD angle becomes more acute, which is an important contributing factor of recurrence, as confirmed in this study. Further studies in larger population is needed to find specific angle that increases the risk of recurrence.

It is well known that bacterial colonization is increased within the bile duct after EST. Extensive dilation of CBD $(\geq 15$ $\mathrm{mm}$ ) increases the likelihood of bacterial infection and cholestasis after EST, acting as a risk factor of CBD stone recurrence. However, maximal diameter of CBD was not found as a risk factor of recurrence in this study. Dilation of CBD often influences the recurrence rate in association with the size of the biliary stone, rather than by itself. ${ }^{19}$ Therefore, EPLBD could easily remove stones of more than $15 \mathrm{~mm}$ in diameter, which explains why the stone recurrence was not affected by dilated CBD in this study. In case of mechanical lithotripsy, there have been reports that small remnant stones might cause biliary stone recurrence, ${ }^{19}$ but we could not perform appropriate analysis with only 1 case of mechanical lithotripsy in the control group. Whether the lack of mechanical lithotripsy case, compared to the previous studies in South Korea on recurrence after EST, ${ }^{22}$ was due to the use of EPLBD only or in combination of limited EST, rather than EST only, or due to the small size of the study population of this study, is not clear; and more prospective studies are warranted in the future with this regard. Some studies have reported that larger CBD stones require more frequent mechanical lithotripsy, increasing the likelihood of recurrence. ${ }^{19}$ In this study, however, stone size was found as a significant risk factor only in the univariate analysis, not in the multivariate analysis, suggesting that the stone size is not relevant to the recurrence.

The number of patients who received ERCP more than twice and the rate of pancreatitis in this study were more increased compared to other studies, which may be explained by the fact that this study included patients unmanageable with conventional EST.

It is generally difficult to conduct a long-term follow-up study on $\mathrm{CBD}$ stone recurrence, because many of the recurrence cases are asymptomatic and these patients often miss the follow-up visits voluntarily without much motivation for regular follow-up. Among patients who received EPLBD only or combination of EPLBD and limited EST in this study, only $35.5 \%(50 / 141)$ of patients were available for regular follow-up with radiologic imaging, which may have introduced a selection bias as a limitation of this study. As the nature of retrospective studies, the fact that the mean follow-up period (10.8 \pm 4.5 months) was shorter than the mean time to recurrence (12.8 \pm 5.6 months), also worked as a limitation of this study to define risk factors of stone recurrence after the therapy.

Follow-up of CBD stone recurrence and identification of risk factors is essential when removing CBD stones using EPLBD only or in combination with limited EST. In clinical practice, high risk patients with identified risk factors should be regularly checked with imaging studies during the follow-up period, for early detection of stone recurrence and reduction of possible complications. $145^{\circ}$ or less distal CBD angle was found, in this study, as an independent risk factor of CBD stone recurrence, and such patients may need to plan shorter follow-up interval with regular imaging studies with or without symptoms.

In conclusion, $145^{\circ}$ or less distal CBD angle on cholangiogram was found as an independent risk factor of $\mathrm{CBD}$ stone recurrence in patients treated with EPLBD only or in combination with limited EST, and regular follow-up is highly recommended in such patients with or without symptoms. However, further studies in larger populations are needed in the future due to the small size of this study population.

\section{Conflicts of Interest}

The authors have no financial conflicts of interest.

\section{REFERENCES}

1. Pereira-Lima JC, Jakobs R, Winter UH, et al. Long-term results (7 to 10 years) of endoscopic papillotomy for choledocholithiasis. Multivariate analysis of prognostic factors for the recurrence of biliary symptoms. Gastrointest Endosc 1998;48:457-464.

2. Cotton PB, Geenen JE, Sherman S, et al. Endoscopic sphincterotomy for stones by experts is safe, even in younger patients with normal ducts. Ann Surg 1998;227:201-204.

3. Freeman ML, Nelson DB, Sherman S, et al. Complications of endoscopic biliary sphincterotomy. N Engl J Med 1996;335:909-918.

4. Ersoz G, Tekesin O, Ozutemiz AO, Gunsar F. Biliary sphincterotomy plus dilation with a large balloon for bile duct stones that are difficult to extract. Gastrointest Endosc 2003;57:156-159.

5. Kim DI, Kim MH, Lee SK, et al. Risk factors for recurrence of primary bile duct stones after endoscopic biliary sphincterotomy. Gastrointest Endosc 2001;54:42-48.

6. Keizman D, Shalom MI, Konikoff FM. An angulated common bile duct predisposes to recurrent symptomatic bile duct stones after endoscopic stone extraction. Surg Endosc 2006;20:1594-1599.

7. Prat F, Malak NA, Pelletier G, et al. Biliary symptoms and complications more than 8 years after endoscopic sphincterotomy for choledocholithiasis. Gastroenterology 1996;110:894-899.

8. Hawes RH, Cotton PB, Vallon AG. Follow-up 6 to 11 years after duodenoscopic sphincterotomy for stones in patients with prior cholecystectomy. Gastroenterology 1990;98:1008-1012.

9. Kim HJ, Choi HS, Park JH, et al. Factors influencing the technical difficulty of endoscopic clearance of bile duct stones. Gastrointest Endosc 2007;66:1154-1160.

10. Lobo DN, Balfour TW, Iftikhar SY, Rowlands BJ. Periampullary diverticula and pancreaticobiliary disease. Br J Surg 1999;86:588-597.

11. Cotton PB, Lehman G, Vennes J, et al. Endoscopic sphincterotomy complications and their management: an attempt at consensus. Gastrointest Endosc 1991;37:383-393.

12. Maydeo A, Bhandari S. Balloon sphincteroplasty for removing difficult bile duct stones. Endoscopy 2007;39:958-961.

13. Baron TH, Harewood GC. Endoscopic balloon dilation of the biliary sphincter compared to endoscopic biliary sphincterotomy for removal of common bile duct stones during ERCP: a metaanalysis of randomized, 
controlled trials. Am J Gastroenterol 2004;99:1455-1460.

14. Fujita N, Maguchi H, Komatsu Y, et al. Endoscopic sphincterotomy and endoscopic papillary balloon dilatation for bile duct stones: a prospective randomized controlled multicenter trial. Gastrointest Endosc 2003;57:151-155.

15. Minami A, Hirose S, Nomoto T, Hayakawa S. Small sphincterotomy combined with papillary dilation with large balloon permits retrieval of large stones without mechanical lithotripsy. World J Gastroenterol 2007;13: 2179-2182.

16. Attasaranya S, Cheon YK, Vittal H, et al. Large-diameter biliary orifice balloon dilation to aid in endoscopic bile duct stone removal: a multicenter series. Gastrointest Endosc 2008;67:1046-1052.

17. Cheon YK, Lehman GA. Identification of risk factors for stone recurrence after endoscopic treatment of bile duct stones. Eur J Gastroenterol Hepatol 2006;18:461-464.
18. Ohashi A, Tamada K, Wada S, et al. Risk factors for recurrent bile duct stones after endoscopic papillary balloon dilation: long-term follow-up study. Dig Endosc 2009;21:73-77.

19. Ando T, Tsuyuguchi T, Okugawa T, et al. Risk factors for recurrent bile duct stones after endoscopic papillotomy. Gut 2003;52:116-121.

20. Miyazawa Y, Okinaga K, Nishida K, Okano T. Recurrent common bile duct stones associated with periampullary duodenal diverticula and calcium bilirubinate stones. Int Surg 1995;80:120-124.

21. Novacek G, Walgram M, Bauer P, Schöfl R, Gangl A, Pötzi R. The relationship between juxtapapillary duodenal diverticula and biliary stone disease. Eur J Gastroenterol Hepatol 1997;9:375-379.

22. Baek YH, Kim HJ, Park JH, et al. Risk factors for recurrent bile duct stones after endoscopic clearance of common bile duct stones. Korean J Gastroenterol 2009;54:36-41. 